\title{
A systematic review and meta-analysis on the efficacy of intravesical therapy for bladder pain syndrome/interstitial cystitis
}

\author{
Jayanta M. Barua ${ }^{1,2}$ - Ignacio Arance ${ }^{3}$ - Javier C. Angulo ${ }^{3}$ - Claus R. Riedl ${ }^{4}$
}

Received: 24 June 2015 / Accepted: 2 November 2015 /Published online: 20 November 2015

(C) The Author(s) 2015. This article is published with open access at Springerlink.com

\begin{abstract}
Bladder pain syndrome/interstitial cystitis (BPS/ IC) is a chronic disease characterised by persistent irritating micturition symptoms and pain. The objective was to compare the clinical efficacy of currently available products for intravesical therapy of BPS/IC and to assess their pharmacoeconomic impact. A Pubmed/Medline database search was performed for articles on intravesical therapy for BPS/IC. A total of 345 publications were identified, from which 326 were excluded. Statistical evaluation was performed with effect size (ES) assessment of symptom reduction and response rates. The final set of 19 articles on intravesical BPS/IC therapy included 5 prospective controlled trials (CTs), the remaining were classified as uncontrolled clinical studies. The total number of patients included was 801, 228 of whom had been evaluated in a CT. For CTs, the largest ES for symptom reduction as well as response rate was observed for high molecular weight hyaluronic acid (HMW-HA), with similar findings in two uncontrolled studies with HMW-HA. The number needed to treat to achieve a response to intravesical therapy was 2.67 for intravesical pentosan polysulphate and 1.31 for HMW-HA which were superior to all other instillates.
\end{abstract}

Claus R. Riedl

riedlc@compuserve.com

1 King George Hospital (BHRUT), Ilford, UK

2 Barts and the London School of Medicine \& Dentistry, QMUL, London, UK

3 Servicio de Urología, Hospital Universitario de Getafe, Universidad Europea de Madrid, Madrid, Spain

4 Department of Urology, Landesklinikum Thermenregion, Wimmergasse 19, 2500 Baden, Austria
HMW-HA was significantly superior in cost effectiveness and cost efficacy to all other instillation regimes. The present meta-analysis combined medical and pharmacoeconomic aspects and demonstrated an advantage of HMW-HA over other instillation agents; however, direct comparisons between the different products have not been performed to date in properly designed controlled studies.

Keywords Bladder pain syndrome · Interstitial cystitis · Intravesical instillation · Hyaluronic acid

$\begin{array}{ll}\text { Abbreviations } \\ \text { BPS/IC } & \text { Bladder pain syndrome/interstitial cystitis } \\ \text { ChS } & \text { Chondroitin sulphate } \\ \text { CT } & \text { Controlled trial } \\ \text { DMSO } & \text { Dimethyl sulfoxide } \\ \text { ES } & \text { Effect size } \\ \text { ESSIC } & \text { International Society for the Study of BPS } \\ \text { FDA } & \text { Food and drug administration } \\ \text { GAG } & \text { Glycosaminoglycans } \\ \text { HA } & \text { Hyaluronic acid } \\ \text { HMW } & \text { High molecular weight } \\ \text { LMW } & \text { Low molecular weight } \\ \text { MW } & \text { Molecular weight } \\ \text { NIDDK } & \text { National Institute of Diabetes and Digestive and } \\ & \text { Kidney Diseases } \\ \text { NNT } & \text { Number needed to treat } \\ \text { PPS } & \text { Pentosan polysulphate } \\ \text { PST } & \text { Potassium sensitivity test } \\ \text { RR } & \text { Response rate } \\ \text { UCT } & \text { Uncontrolled trial } \\ \text { VAS } & \text { Visual analogue scale } \\ & \end{array}$




\section{Introduction}

Bladder pain syndrome/interstitial cystitis (BPS/IC) is a chronic disease characterised by persistent irritating micturition symptoms and pain [1]. While there is no general agreement on the precise pathophysiology of this disease, a disorder at the level of the urine-tissue barrier of the bladder seems to be the underlying mechanism behind the functional, anatomical and symptomatic manifestations in a considerable number of cases.

Even if study results are not entirely consistent and, therefore, the subject is not closed, a defect in the protective bladder's mucous lining of glycosaminoglycans (GAG) and, thus, the urine-tissue barrier, has been documented in a subset of BPS/IC patients [2], mainly demonstrated by a positive potassium sensitivity test (PST) [3-6] and the favourable response to GAG-restoring agents.

Glycosaminoglycans are classified in four structural families [7] (heparin and heparan sulphates; chondroitin and dermatan sulphates; hyaluronan; and keratan sulphate) and have been used during the last few decades as intravesical instillations for GAG substitution therapy with the benefit of delivering high concentrations of the therapeutic agent at the target tissue with a low risk of systemic side effects [8].

The diversity of available therapeutic agents for GAG substitution may make it difficult for physicians to choose the optimal treatment for their patients $[9,10]$; therefore, the selection of a particular therapeutic regimen should be based on its capacity for symptom improvement, its impact on the patient's quality of life, and its costs [10].

Heparin has commonly been used off-label for BPS/IC therapy. Pentosan polysulphate (PPS), a semisynthetic heparin-like GAG of low molecular weight (MW) classically used for oral therapy of BPS/IC, is also available for intravesical instillation. Today, hyaluronan, the salt of hyaluronic acid (HA), and chondroitin sulphate (ChS) are the two most commonly used GAGs for intravesical treatment, alone or in combination.

Other intravesical instillations containing anaesthetic solutions, such as lidocaine and bupivacaine, are also used in combination with sodium bicarbonate to control bladder pain [11], while dimethyl sulfoxide (DMSO), which has a putative effect on the sensory peripheral nerves of the bladder [12], is the only intravesical therapy approved by the FDA.

At present, eight agents for intravesical BPS/IC therapy are commercially available in Europe (Table 1)

Despite the widespread clinical use of each of these substances, the research-based evidence regarding therapeutic efficacy is limited and mainly based on uncontrolled trials. Levels of evidence for the use of these agents have been rated $1 \mathrm{~b}$ for PPS and heparin, and $2 \mathrm{~b}$ for HA and $\mathrm{ChS}$ in their different concentrations [13].
Table 1 Intravesical agents for bladder pain syndrome/interstitial cystitis (BPS/IC) therapy, their registered trade names and pharmacological composition

\begin{tabular}{|c|c|c|}
\hline $\begin{array}{l}\text { Intravesical } \\
\text { agent }\end{array}$ & $\begin{array}{l}\text { Registered } \\
\text { trade name }\end{array}$ & Composition \\
\hline \multirow[t]{3}{*}{ HA } & Cystistat $^{\mathbb{R}}$ & 40 mg HMW-HA (0.08 \%) in $50 \mathrm{ml}$ \\
\hline & Hyacyst ${ }^{\circledR}$ & $\begin{array}{l}\text { 40/120 mg HA }(0.08 / 0.24 \%) \text { in } 50 \mathrm{ml} \\
\text { (MW unknown) }\end{array}$ \\
\hline & Uromac $^{\circledR}$ & $100 \mathrm{mg}$ LMW HA (0.2 \%) in $50 \mathrm{ml}$ \\
\hline \multirow[t]{2}{*}{$\mathrm{CS}$} & Gepan instill $^{\mathbb{R}}$ & $80 \mathrm{mg} \mathrm{CS}(0.2 \%)$ in $40 \mathrm{ml}$ \\
\hline & Uracyst $^{\circledR}$ & $400 \mathrm{mg} \mathrm{CS}(2 \%)$ in $20 \mathrm{ml}$ \\
\hline $\mathrm{HA} / \mathrm{CS}$ & Ialuril ${ }^{\circledR}$ & $\begin{array}{l}800 \mathrm{mg} \text { LMW-HA }(1.6 \%) / 1 \mathrm{~g} \mathrm{CS}(2 \%) \\
\text { in } 50 \mathrm{ml}\end{array}$ \\
\hline PPS $^{\mathrm{a}}$ & Cyst-u-ron ${ }^{\circledR}$ & $300 \mathrm{mg}$ PPS (1\%) in $30 \mathrm{ml}$ \\
\hline DMSO & Rimso- $50^{\circledR}$ & $27 \mathrm{~g}$ DMSO $(5.4 \%)$ in $50 \mathrm{ml}$ \\
\hline
\end{tabular}

$H A$ hyaluronan, $C S$ chondroitin sulphate, $P P S$ pentosan polysulphate sodium, $D M S O$ dimethyl sulfoxide, $H M W$ high molecular weight, $M W$ molecular weight, $L M W$ low molecular weight

${ }^{\mathrm{a}}$ Elmiron ${ }^{\circledR}$ is the oral form of pentosan polysulphate sodium $(100 \mathrm{mg})$

The aim of this meta-analytical review is to directly compare the data on the clinical efficacy of products currently available for intravesical BPS/IC therapy and to assess their pharmacoeconomic impact to assist in therapeutic decisionmaking.

\section{Materials and methods}

\section{Literature search}

Preferred Reporting Items for Systematic reviews and MetaAnalyses (PRISMA) [14] guidelines were used to perform a comprehensive search for literature on intravesical therapy for BPS/IC and published in the PubMed/Medline database from 1996 to 2014. The Medical Subject Heading (MESH) search terms used were: interstitial cystitis, bladder pain syndrome, intravesical treatment, intravesical chondroitin sulphate, intravesical hyaluronan, intravesical PPS, intravesical DMSO, and intravesical lidocaine.

\section{Selection criteria}

The PubMed/Medline search allowed us to identify publications regarding intravesical treatment for BPS/IC. From these, only studies in English or Spanish reporting clinical results were reviewed. Further analysis included only studies with a single compound or a fixed commercially available combination. Studies were excluded if they:

1. Were performed using intravesical "cocktails"

2. Did not evaluate intravesical treatment for BPS/IC 
3. Assessed other related topics, but did not evaluate treatment efficacy (case reports, conference reports etc.)

4. Were defined as review or meta-analysis papers

\section{Data extraction and statistical analysis}

Data were extracted from each publication by two independent reviewers (CLL and AMG) and included: type of study according to the presence of a control arm (controlled or uncontrolled clinical trials), randomisation (randomised or nonrandomised controlled trials) and observational studies (prospective or retrospective), type of intravesical solution, total of patients at baseline (intention-to-treat analysis), total patients treated (per protocol analysis), number of patients lost to follow-up, therapy regimen (total number of instillations/ frequency of application), instruments/scales used for evaluation of symptoms before and after treatment, and response rates (RR), considered as the percentage of patients with symptom reduction after therapy out of the total study sample [15]. In the absence of an explicitly cited definition for RR, and according previous publications [16, 17], a reduction of $\geq 2$ on a visual analogue scale (VAS) was considered to be a response to treatment; the percentage of responders was inferred by calculating the $\mathrm{z}$ value, defined as the proportion of responders within confidence intervals at $95 \%$ (CI $95 \%$ ).

The different products were compared with regard to the average reduction of bladder symptoms on the VAS and the overall response rates by calculation of "Cohen's d" [18], a statistical value for effect size (ES) based on differences between mean values and the average difference in the proportion of patients with a response to treatment and allows the difference between the two groups to be quantified using the standard deviation. While the broadly accepted and cited $p$ value informs whether an effect from the investigated measure exists, it does not reveal the size of the effect. For Cohen's $d$, a low value $<0.5$ shows a small $\mathrm{ES}, \mathrm{d}$ values $>1$ are regarded as large ES.

From the CTs, a post-hoc calculation of a composite VAS/ RR odds ratio (OR) allowed the comparison of results of different intravesical agents with the placebo/control-treated arms. These values were also used to calculate the number of patients needed to treat (NNT) to obtain a response.

Finally, the pharmacoeconomic assessment was performed by multiplying the unit costs by the number of instillations administered in each CT. Costs per unit and frequency of instillation (one per week) are very similar for HA and $\mathrm{ChS}$ products; thus, a cost factor of 1 has been assigned for these two therapies. PPS is less expensive (instillation units cost $40 \%$ of $\mathrm{HA} / \mathrm{ChS}$, oral therapy $20 \%$ ), but has to be administered two or three times per week and may be accompanied by oral therapy, Thus, a cost factor of 0.4 for intravesical/ 0.6 for intravesical and oral therapy has been assumed for PPS trials.

\section{Results}

The Medline search led to a total of 345 hits. Initially, all titles and abstracts were reviewed to identify studies not directly reporting on BPS/IC or intravesical treatment for BPS/IC, reviews, and other type of publications not suitable for this analysis.

From the 33 studies selected according to the outlined criteria, $11(33.33 \%)$ assessed intravesical therapy with HMW-HA $0.08 \%$ (of which one paper also evaluated intravesical heparin), 7 studies presented the results of $\mathrm{ChS}$ $0.2 \%$ therapy $(21.21 \%$ ), and 3 studies evaluated treatment with $\mathrm{ChS} 2.0 \%(9.09 \%)$. Results of the combined formulation of LMW-HA $+\mathrm{ChS} 2.0 \%$ were presented in 4 publications $(12.12 \%), 3$ papers assessed the results of intravesical treatment with PPS (9.09\%), 2 with lidocaine (6.06\%), and another 3 articles reported results with DMSO (9.09\%). No publications on LMW-HA alone for the treatment of BPS/IC were retrieved from the search.

The main criteria for the exclusion of studies were reports on combination therapies with non-GAG substances, duplicity of results (same sample of patients), and results not comparable in a standardised way because of the different instruments used for outcome evaluation. Thus, 2 of the articles on HMW-HA therapy were excluded from further analysis because they involved combination with alkalised lidocaine [19] or oral PPS [20]. Similarly, 2 publications on DMSO were excluded because of combination therapies (DMSO + hydrocortisone + heparin sulphate [21] and DMSO + triamcinolone [22]). One study with the combination of LMW-HA $1.6 \%+\mathrm{ChS} 2.0 \%$ [23] was excluded owing to obvious coincidences with another publication [24].

The majority of the selected publications referred to BPS/ IC therapy, except for 2 papers on $\mathrm{ChS} 0.2 \%$, which evaluated the product in patients with overactive bladder $[25,26]$ and for the prophylaxis of radiation cystitis [27]; 2 of the excluded articles reported on the efficacy of a combination of heparin and lidocaine as an acute analgesic intervention for severe pain $[28,29]$.

Two publications on HMW-HA $0.08 \%$ therapy were excluded because they evaluated symptoms with different nonstandardised scales [30,31], and in one study in which patients received intravesical instillations with LMW-HA $1.6 \%$ $+\mathrm{ChS} 2.0 \%$ data on VAS pain scores were missing [32]. The full text version of one publication for ChS $0.2 \%$ [33] could not be found after searching several databases. In summary, 14 publications were excluded (Fig. 1).

The final set of 19 articles on intravesical BPS/IC therapy was further qualitatively and quantitatively analysed: 5 studies were prospective controlled trials [34-38], 1 compared different intravesical products [39], 1 paper was designed as a retrospective study [40], and another 1 compared two different regimens of the same product [41]. The 


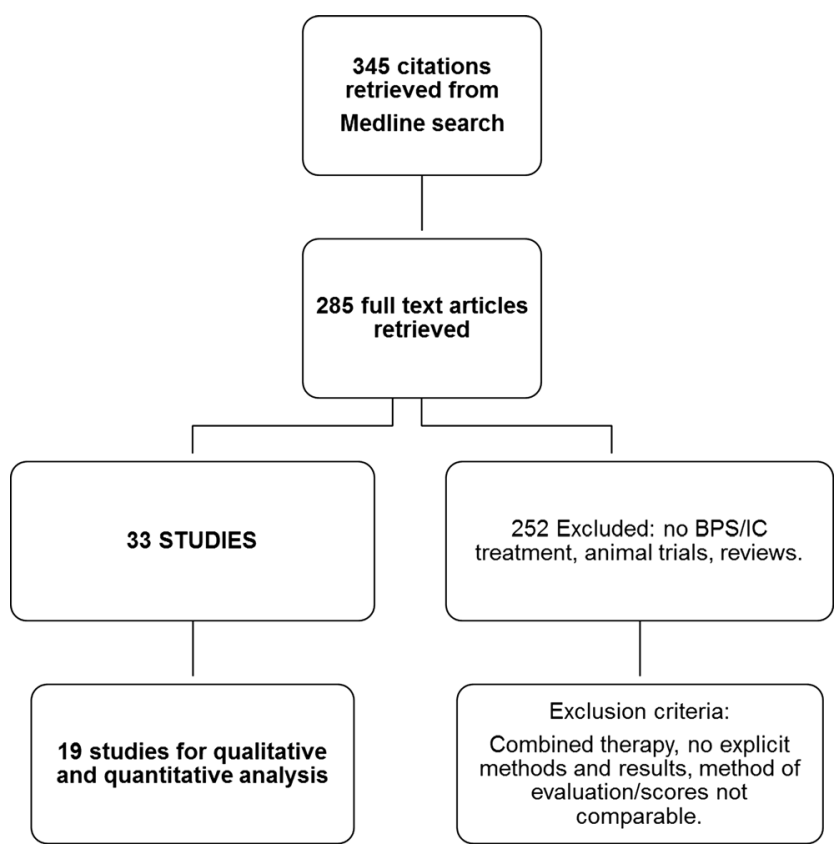

Fig. 1 Selection process of the studies included for analysis

rest of the trials were classified as uncontrolled clinical studies (Table 2).

\section{Patients characteristics}

The final sample of 19 trials corresponds to a total of 801 patients, with 228 patients evaluated in a CT. Only 4 trials included male and female patients [15, 35, 44, 45], while the rest of the studies exclusively included women.

Diagnosis of BPS/IC has been made according to NIDDK/ National Institutes of Health criteria in most studies (one including cystoscopic examination [42]), except for three publications (ESSIC criteria [40], the East Asian guidelines [41] or clinical perception plus cystoscopy [38]).

Other relevant differences were also detected: six of the studies included "treatment-refractory patients", considered to be cases with an inadequate response to previous BPS/IC treatments such as intravesical DMSO [15], heparin and/or PPS [15, 41] and/or oral drug therapy [24, 43, 47]. One study only included "naïve patients" (no previous disease-specific treatment) with a positive PST and a reduction of $\geq 2$ points in symptom score after the first instillation of ChS $0.2 \%$ [44].

\section{Instillation regimen}

Initial instillation therapy was performed weekly in $73.7 \%$ of the studies, but with different follow-up schedules (Table 2). The instillation procedure was similar in most studies, with the exception of one trial, where a solution of lidocaine and sodium bicarbonate was instilled before the PPS to reduce the procedure-related discomfort and to improve the retention of the subsequently instilled PPS [38].

\section{Evaluation of efficacy}

In most studies a first symptom evaluation was performed at week 12; however, different scales/scores were used. Among them, the most commonly used were the O'Leary-Sant Symptom and Problem Index (ICSI/ICPI), the VAS pain assessment and the Pain, Urgency and Frequency (PUF) score.

According to their design, studies were classified as controlled (Table 3) and uncontrolled (Table 4) trials. All the studies reviewed reported reductions of VAS pain scores after treatment, including those controlled using placebo/inactive controls (Table 3). The ES of VAS reduction was calculated for each $\mathrm{CT}$ and showed significant differences between active and control groups in all but one study, which compared $\mathrm{ChS}$ $2 \%$ with a placebo arm [36]. The largest ES in all CT studies was observed for HMW-HA in the study by Shao et al. (Fig. 2) [34], with similar findings in two UCT studies with HMW-HA $[16,40]$ by a superior " $\mathrm{d}$ " for average VAS difference. Closest to this VAS reduction were the results obtained using $300 \mathrm{mg}$ of intravesical PPS [47].

Response rates were compared between intervention arms by ES assessment only in the trial by Shao et al. [34] with HMW-HA $(\mathrm{d}=2.68$ [IC95\%:1.82-3.53] vs $\mathrm{d}=0.88$ [IC95\%:0.01-1.76]) for patients without intravesical therapy (Fig. 3). In CTs, studies with HMW-HA and with ChS $0.2 \%$ reported superior response rates, with both rates (HMW-HA vs $\mathrm{ChS} 0.2 \%$ ) not being statistically different.

The post-hoc calculation of composite ES based on VAS improvement plus RR revealed distinct differences among studies and products as shown in Fig. 4. OR value was highest for HMW-HA in the Shao et al. study [34], followed by the intravesical application of $300 \mathrm{mg}$ of PPS described by Bade et al. [37].

\section{Pharmacoeconomic evaluation/cost-effectiveness}

The NNT for a response to intravesical therapy ranged between 1.33 (HMW-HA) and 14.81 (ChS $2 \%$ ), with a negative value for the PPS combination therapy (Table 5). With this low NNT, HMW-HA was also significantly superior with regard to cost-effectiveness and cost efficacy to all other instillation regimes.

\section{Discussion}

The present meta-analysis on intravesical BPS/IC therapy clearly demonstrates the dilemma of the poor scientific evidence currently available for this disease. Owing to the different associations regarding the aetiology of the disease and its 
Table 2 All studies included for comparison

\begin{tabular}{|c|c|c|c|c|c|c|}
\hline Study (reference) & Treatment & $\begin{array}{l}\text { Type of } \\
\text { study }\end{array}$ & $\begin{array}{l}\text { Total } \\
\text { sample }\end{array}$ & Instillation protocol & Follow-up & Evaluation scale \\
\hline Morales et al. [15] & \multirow[t]{8}{*}{$\begin{array}{l}0.8 \% \text { HMW-HA } \\
\left(\text { Cystistat }^{\circledR}\right)\end{array}$} & UCT & 25 & $\begin{array}{l}\text { Weekly for } 4 \text { weeks and monthly for } \\
12 \text { months }\end{array}$ & 12 months & VAS for pain \\
\hline Kallestrup et al. [42] & & UCT & 48 & $\begin{array}{l}\text { Weekly for } 4 \text { weeks and monthly for } \\
2 \text { months }\end{array}$ & 3 years & VAS for pain \\
\hline Gupta et al. [43] & & UCT & 38 & Weekly for 6 weeks & 6 weeks & ICSI-ICSP \\
\hline Riedl et al. [16] & & UCT & 121 & Weekly and in response to symptoms & 6.5 months & VAS for pain \\
\hline Engelhardt et al. [40] & & UCT & 70 & Weekly for 10 weeks & 4.9 years & VAS for pain \\
\hline Shao et al. [34] & & $\mathrm{CT}$ & 31 & $\begin{array}{l}\text { After hydrodistention, weekly for } \\
4 \text { weeks and monthly for } 2 \text { months }\end{array}$ & 9 months & VAS for pain \\
\hline Lai et al. protocol A ${ }^{a}[41]$ & & UCT & 30 & $\begin{array}{l}\text { Weekly for } 4 \text { weeks and monthly for } \\
5 \text { months }\end{array}$ & 6 months & VAS for pain/ICSI-ICPI \\
\hline Lai et al. protocol B ${ }^{a}[41]$ & & UCT & 30 & Every 2 weeks & 6 months & VAS for pain/ICSI-ICPI \\
\hline Steinhoff [44] & \multirow[t]{2}{*}{$\begin{array}{l}0.2 \% \text { CS (Gepan } \\
\left.\quad \text { instill }^{\circledR}\right)\end{array}$} & UCT & 18 & $\begin{array}{l}\text { Weekly for } 4 \text { weeks and monthly for } \\
12 \text { months }\end{array}$ & 12 months & ICSI-ICPI \\
\hline $\begin{array}{l}\text { Nordling and van } \\
\text { Ophoven [45] }\end{array}$ & & UCT & 165 & $\begin{array}{l}\text { Weekly for } 4 \text { to } 6 \text { weeks and one } \\
\text { monthly }\end{array}$ & 3 months & VAS for pain \\
\hline Nickel et al. [46] & \multirow[t]{3}{*}{$\begin{array}{l}2 \% \mathrm{CS}_{\left(\mathrm{Uracyst}^{\circledR} /\right.} \\
\left.\text { Uropol } \mathrm{S}^{\circledR}\right)\end{array}$} & UCT & 53 & $\begin{array}{l}\text { Weekly for } 6 \text { weeks and monthly for } \\
4 \text { months }\end{array}$ & 6 months & VAS for pain/ICSI-ICPI \\
\hline Nickel et al. [35] & & $\mathrm{CT}$ & 65 & Weekly for 6 weeks & 3 months & VAS for pain/ICSI-ICPI \\
\hline Nickel et al. [35] & & $\mathrm{CT}$ & 98 & Weekly for 7 weeks & 3 months & VAS for pain/ICSI-ICPI \\
\hline Porru et al. [24] & \multirow[t]{2}{*}{$\begin{array}{l}1.6 \% \text { LMW-HA + } 2 \% \\
\quad \text { CS (Ialuril }{ }^{\mathbb{R}} \text { ) }\end{array}$} & UCT & & $\begin{array}{l}\text { Weekly for } 12 \text { weeks and biweekly } \\
\text { for } 6 \text { months }\end{array}$ & 6 months & VAS for pain/ICSI-ICPI \\
\hline Porru et al. [47] & & UCT & 22 & $\begin{array}{l}\text { Weekly for } 8 \text { weeks and biweekly for } \\
6 \text { months }\end{array}$ & 6 months & VAS for pain/ICSI-ICPI \\
\hline Bade et al. [48] & \multirow{3}{*}{$\begin{array}{l}\text { i-PPS } 300 \mathrm{mg}^{\mathrm{b}} \\
\quad\left(\text { Elmiron }^{\mathbb{R}}\right)\end{array}$} & UCT & 20 & Every 2 weeks for 3 months & 3 months & Not available \\
\hline Bade et al. [37] & & $\mathrm{CT}$ & 9 & Twice weekly for 3 months & 3 months & ICSI/ICPI \\
\hline Daha et al.[17] & & UCT & 29 & $\begin{array}{l}\text { Twice weekly for } 10 \text { weeks; monthly } \\
\text { for } 6 \text { months }\end{array}$ & 12 months & ICSI/ICPI \\
\hline Davis et al. [38] & $\begin{array}{l}\text { i-PPS } 200 \mathrm{mg}^{\mathrm{c}}+\text { daily } \\
\text { o-PPS } 400 \mathrm{mg} \\
\left(\text { Elmiron }^{\circledR}\right)\end{array}$ & $\mathrm{CT}$ & 41 & Twice a week for 18 weeks & 18 weeks & VAS for pain/ ICSI-ICPI \\
\hline Sairanen et al. [39] & DMSO & UCT & 37 & Weekly for 6 weeks & 3 months & VAS for pain \\
\hline
\end{tabular}

$C T$ controlled trials, UCT uncontrolled trials, VAS visual analogue scale, ICSI/ICPI O'Leary-Sant symptom index and problem index, $i-P P S$ intravesical PPS, o-PPS oral PPS

${ }^{\mathrm{a}}$ Lai et al. corresponds to two effective protocols with HMW-HA evaluated in the same publication

${ }^{\mathrm{b}}$ Intravesical instillation with $300 \mathrm{mg}$ (three capsules) of Elmiron ${ }^{\circledR}+$ mixed with $50 \mathrm{ml}$ of $0.9 \%$ sodium chloride

c $200 \mathrm{mg}$ or two capsules mixed with $30 \mathrm{ml}$ sterile normal buffered saline

rather low prevalence, most published studies cohorts are heterogeneous. The lack of globally accepted instruments for the evaluation of treatment success resulted in the exclusion of some trials from this meta-analytical review because the reported outcomes were not comparable.

Even after a careful selection of 19 studies, we still found a heterogeneous population of 801 patients (mostly women) who were considered to have BPS/IC according to four different diagnostic criteria and typified as "treatment-refractory" (a concept that is not further defined) in 6 studies or as "treatment-naïve" patients in 1 study. Differences in design are also of particular relevance as only 5 studies ( $26 \%$ compared the intravesical formulas against placebo or non-active controls, while the remainder corresponded to uncontrolled and observational trials.
Length of treatment and frequency of instillations also differed: weekly instillations were initially performed in 15 studies, biweekly or twice weekly instillations were reported for 2 studies each, while the duration of instillation therapy varied from 6 weeks to 12 months. Similarly, the time period of follow-up for final evaluation varied from 3 months to 5 years.

All the instruments/scales used for outcome evaluation (O'Leary-Sant Score, the PUF and VAS for pain) can potentially measure treatment effects, but they are not readily comparable with each other. There is also no globally accepted definition as to the percentage of symptom regression that is regarded as treatment response. In addition, relatively small differences in VAS scores before and after treatment may be statistically but probably not clinically significant. With the intention to improve the balance between investigational and 


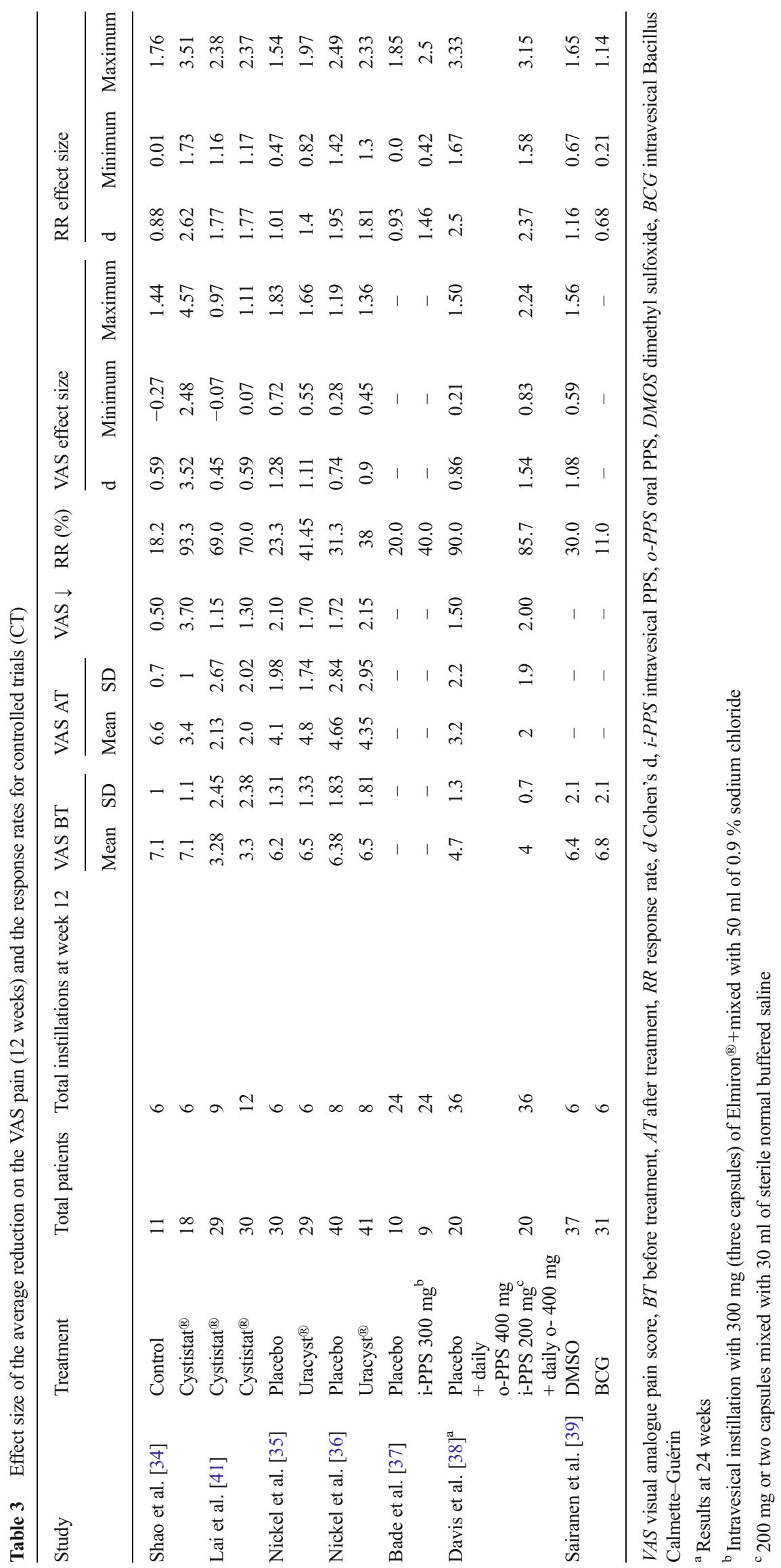


Table 4 Effect size results for uncontrolled trials (UCT)

\begin{tabular}{|c|c|c|c|c|c|c|c|c|c|c|c|c|c|c|c|}
\hline \multirow[t]{2}{*}{ Study } & \multirow[t]{2}{*}{ Treatment } & \multirow{2}{*}{$\begin{array}{l}\text { Total } \\
\text { patients }\end{array}$} & \multirow{2}{*}{$\begin{array}{l}\text { Number of } \\
\text { instillations } \\
(12 \text { weeks })\end{array}$} & \multicolumn{2}{|c|}{ VAS BT } & \multicolumn{2}{|c|}{ VAS AT } & \multirow[t]{2}{*}{ VAS $\downarrow$} & \multirow[t]{2}{*}{ RR (\%) } & \multicolumn{3}{|c|}{ VAS effect size } & \multicolumn{3}{|c|}{ RR effect size } \\
\hline & & & & Mean & $\mathrm{SD}$ & Mean & SD & & & d & Min & Max & $\mathrm{d}$ & Min & Max \\
\hline Morales et al. [15] & \multirow{5}{*}{$\begin{array}{l}0,8 \% \text { HMW-HA } \\
\quad\left(\text { Cystistat }^{\circledR}\right)\end{array}$} & 25 & 6 & 6.7 & 2.45 & 2.7 & 3.67 & 4.00 & 71.0 & 1.31 & 0.70 & 1.92 & 2.00 & 1.32 & 2.68 \\
\hline Kallestrup et al. [42] & & 20 & 6 & 4.7 & 2.3 & 3.3 & 3.0 & 1.40 & 65.0 & 0.53 & -0.10 & 1.16 & 1.88 & 1.13 & 2.62 \\
\hline Gupta et al. ${ }^{\mathrm{a}}$ [43] & & 20 & 6 & - & - & - & - & - & 55.6 & - & - & - & 1.68 & 0.96 & 2.40 \\
\hline Riedl et al. [16] & & 121 & 12 & 8.5 & 1.7 & 3.5 & 2.7 & 5.00 & 85.0 & 2.27 & 1.95 & 2.60 & 2.35 & 2.02 & 2.67 \\
\hline Engelhardt et al. [40] & & 48 & 10 & 8.15 & 1.7 & 2.71 & 1.96 & 5.44 & 85.0 & 2.97 & 2.39 & 3.55 & 2.35 & 1.83 & 2.87 \\
\hline Steinhoff $^{b}[44]$ & \multirow{2}{*}{$\begin{array}{l}0.2 \% \text { CS } \\
\left(\text { Gepan instill }{ }^{\circledR}\right)\end{array}$} & 13 & - & - & - & - & - & - & 92.3 & - & - & - & 2.58 & 1.83 & 3.33 \\
\hline $\begin{array}{c}\text { Nordling and van } \\
\text { Ophoven [45] }\end{array}$ & & 165 & 8 & 5.2 & 2.57 & 3.3 & 2.57 & 1.90 & 76.7 & 0.74 & 0.52 & 0.96 & 2.13 & 1.86 & 2.4 \\
\hline Nickel et al. [46] & 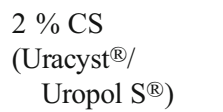 & 53 & 10 & 6.9 & 1.8 & 4.3 & 2.3 & 2.60 & 60.0 & 1.27 & 0.85 & 1.69 & 1.77 & 1.32 & 2.22 \\
\hline Porru et al. [24] & \multirow{2}{*}{$\begin{array}{c}1,6 \% \mathrm{HA}+2 \% \\
\text { CS (Ialuril }{ }^{\mathbb{R}} \text { ) }\end{array}$} & 23 & 12 & 5.4 & 2.8 & 3.6 & 2.5 & 1.80 & 46.0 & 0.68 & 0.08 & 1.27 & 1.49 & 0.84 & 2.14 \\
\hline Porru et al. [47] & & 20 & 10 & 5.6 & 2.3 & 3.2 & 3.1 & 2.40 & 53.48 & 0.89 & 0.24 & 1.54 & 1.64 & 0.92 & 2.36 \\
\hline Bade et al. [48] & \multirow[t]{2}{*}{ i-PPS $300 \mathrm{mg}$} & 6 & 24 & 7.5 & 1.38 & 4.17 & 2.3 & 3.33 & 66.7 & 1.81 & 0.47 & 3.15 & 1.91 & 0.55 & 3.28 \\
\hline Daha et al. [17] & & 25 & 22 & - & - & - & - & - & 16.0 & - & - & - & 0.82 & 0.25 & 1.4 \\
\hline
\end{tabular}

$V A S$ visual analogue pain score, $B T$ before treatment, $A T$ after treatment, $R R$ response rate, $d=$ Cohen's d, $i-P P S$ intravesical instillation with $300 \mathrm{mg}$ (three capsules) of Elmiron ${ }^{\circledR}+$ mixed with $50 \mathrm{ml}$ of $0.9 \%$ sodium chloride

${ }^{\text {a }} 6$ weeks

b 24 weeks

clinical outcomes, and to extract the maximal information from the selected set of evaluable studies on intravesical BPS/IC therapy, refined statistical techniques such as Cohen's $d$ along with confidence intervals have been used in this meta-analytical review to be able to compare the selected set of evaluable studies.
Interestingly, symptom improvement was observed in all cases, including those from the placebo/non-active treatment arms. By far the largest effect sizes $(\mathrm{d}>2)$ for symptom reduction were found in 3 studies performed with HMW-HA [16, 34, 40].

With respect to response rates, effect size measurements showed similar results for HMW-HA and $0.2 \% \mathrm{ChS}$, and
Fig. 2 Randomised controlled trials: effect size of average VAS reduction. $95 \%$ CI $95 \%$ confidence intervals, $H M W-H A$ high molecular weight hyaluronic acid $0.08 \%$, ChS $2 \%$ chondroitin sulphate $2 \%, o-P P S$ oral dose of pentosan polysulphate, $i$ - PPS intravesical instillation with pentosan polysulphate

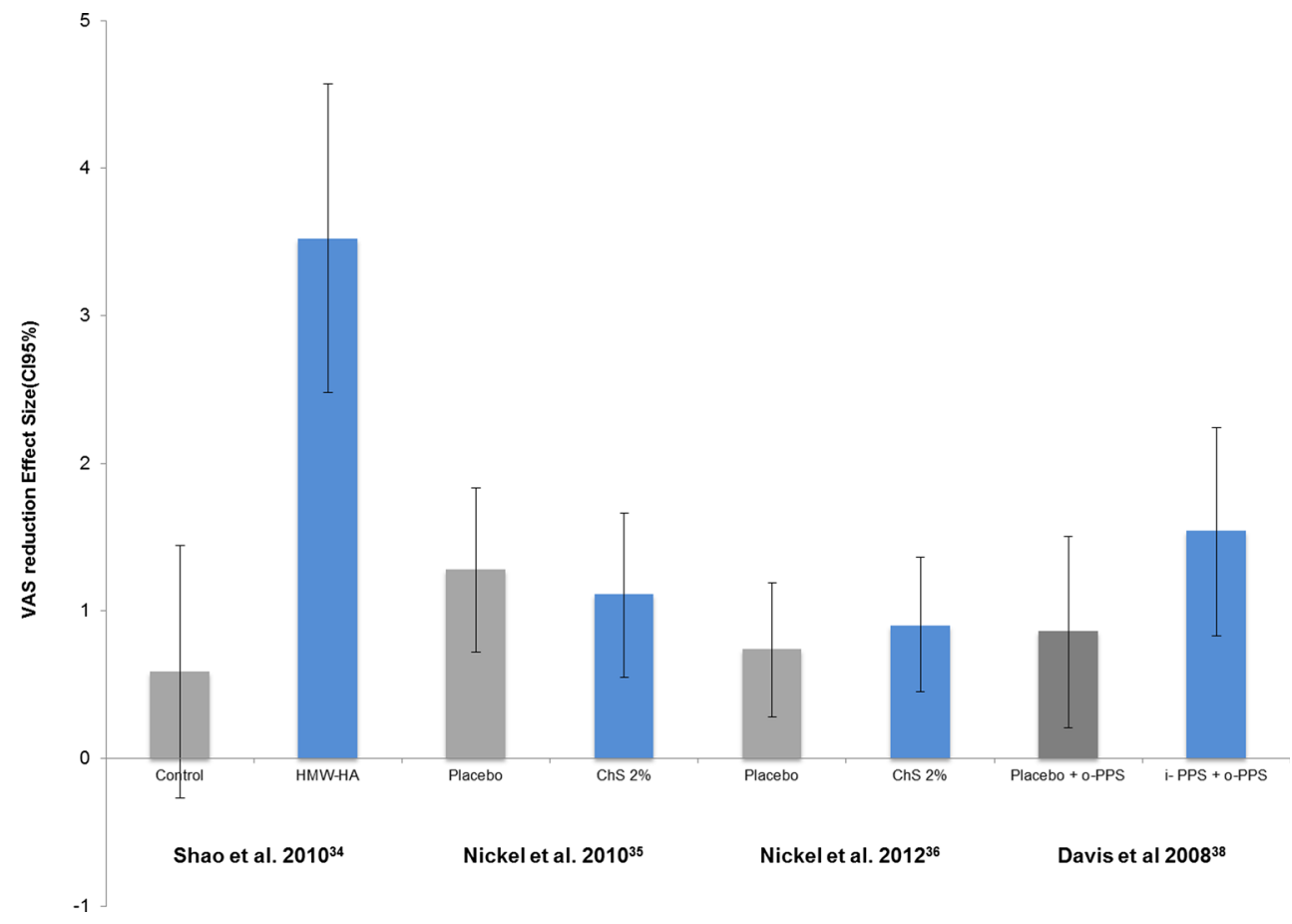


Fig. 3 Randomised controlled trials: effect size of the response rates. $95 \% C I 95 \%$ confidence intervals, $H M W-H A$ high molecular weight hyaluronic acid $0.08 \%, C h S 2 \%$ chondroitin sulphate $2 \%, o$-PPS oral dose of pentosan polysulphate, $i$ - PPS intravesical instillation with pentosan polysulphate

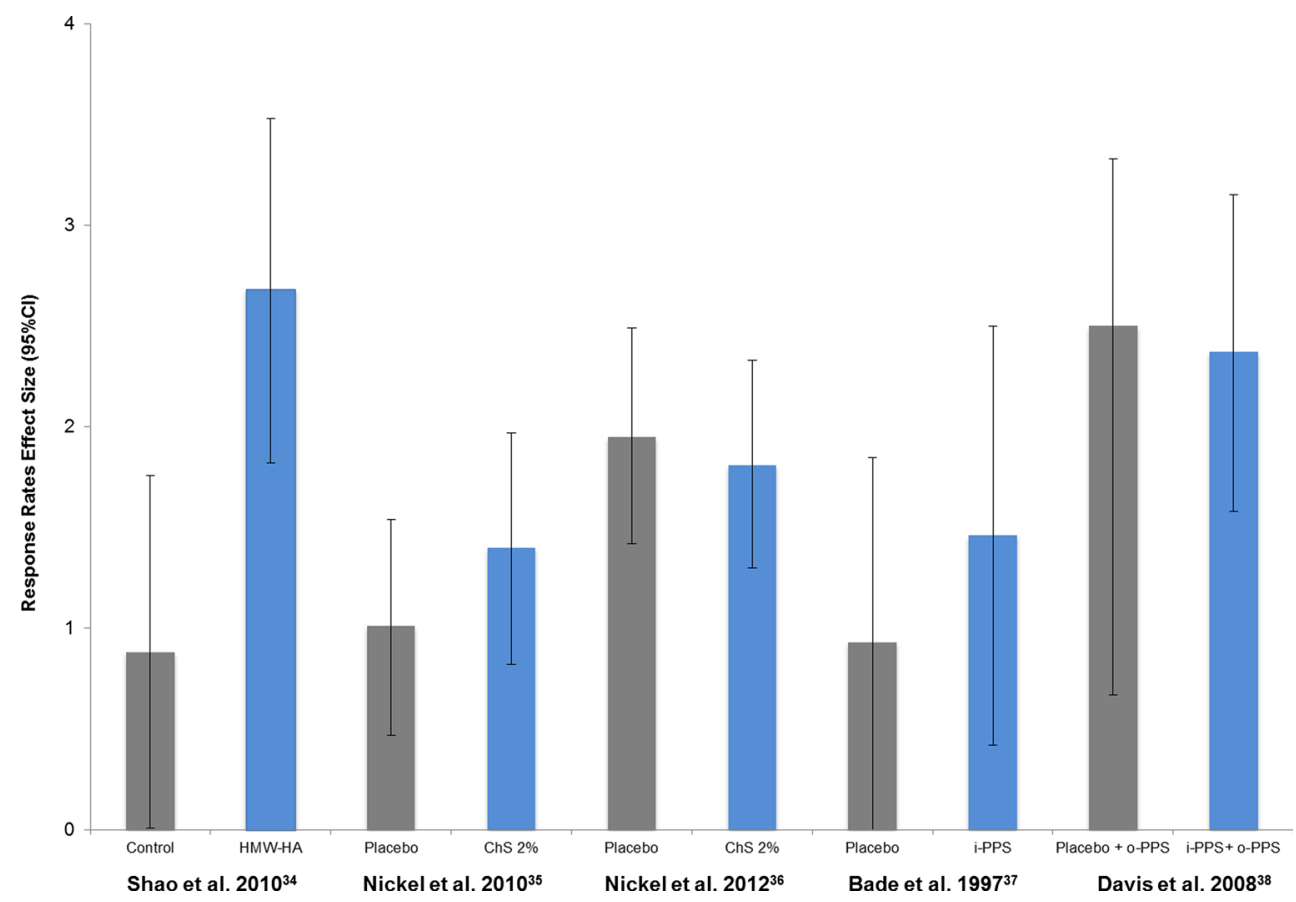

for PPS. If only CTs were included in the analysis, HMW-HA was significantly superior to all other instillates (Table 3 ). The closest results on efficacy were observed with intravesical PPS [37] and a combination of intravesical plus oral PPS [38]; this last combined strategy reported by Davis et al. [38], however, showed a higher RR in patients who received oral PPS alone (90 vs $85.7 \%$ ).

In the pharmacoeconomic approach of CTs, a clear advantage for HMW-HA was observed: the NNT for a treatment response was 1.31 for HMW-HA vs 2.74 for intravesical PPS and 5.51 for ChS $2 \%$. Cost efficacy (treatment costs * NNT) and cost effectiveness (treatment costs/responders) were higher for HMW-HA. Cost effectiveness was less than half for $\mathrm{ChS}$ and only about a third for PPS compared with HMW-HA, and cost efficacy was less than $25 \%$ for ChS compared with HMW-HA. However, these results are based on a small number of studies with final analysis.

Fig. 4 Composite effect size of response rates and VAS reduction: active treatments versus placebo (OR 95\% CI). 95\% CI $95 \%$ confidence intervals, $V A S$ visual analogue scale of pain, $O R$ odds ratio

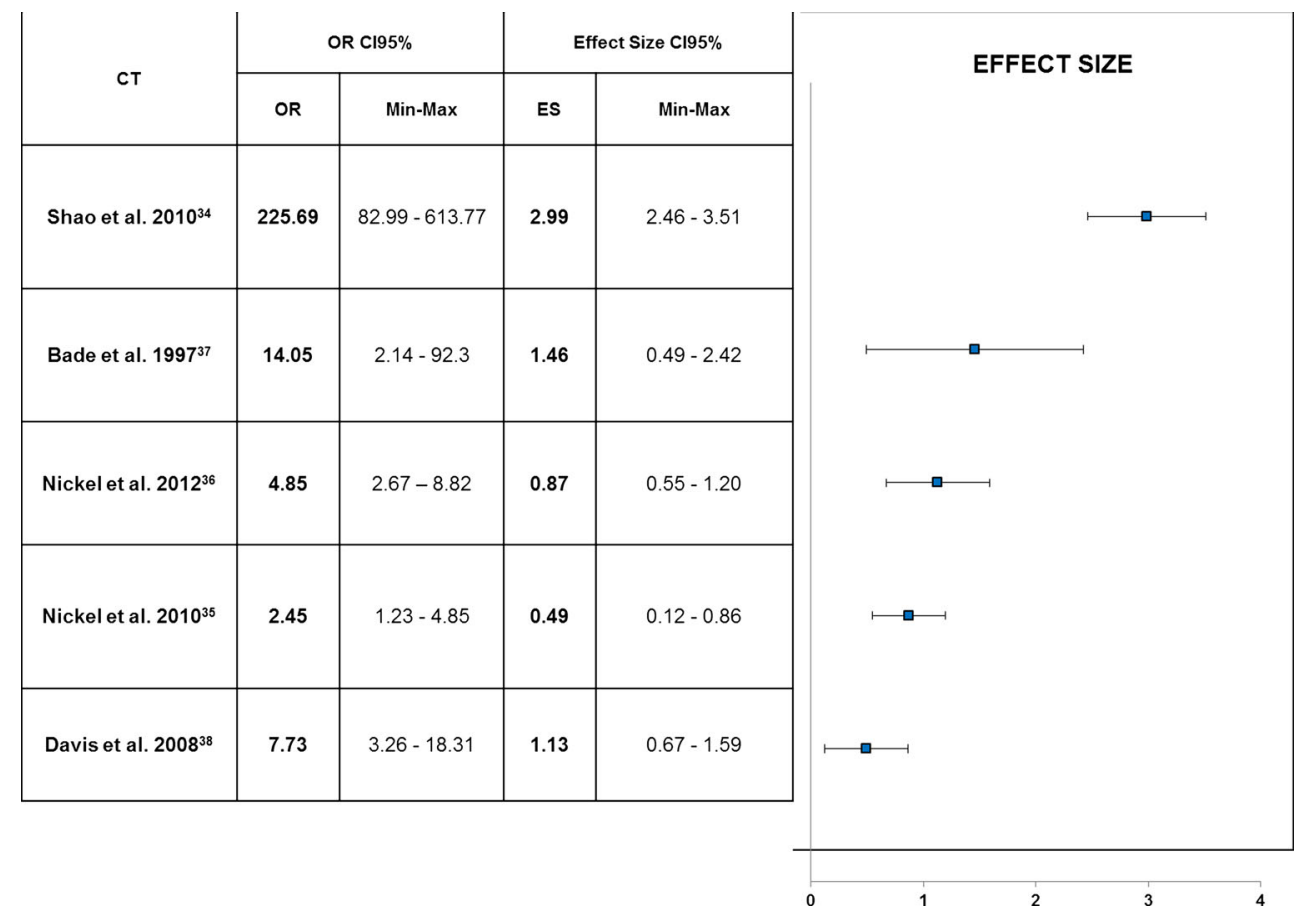


Table 5 Pharmacoeconomic evaluation

\begin{tabular}{|c|c|c|c|c|c|}
\hline \multirow{2}{*}{$\begin{array}{l}\text { Product } \\
\text { Study }\end{array}$} & \multirow{2}{*}{$\begin{array}{l}\begin{array}{l}\text { HMW-HA } 0.08 \% \\
\left(\text { Cystistat }^{\circledR}\right)\end{array} \\
\text { Shao et al. [34] }\end{array}$} & \multicolumn{2}{|c|}{$2 \%$ CS (Uracyst ${ }^{\circledR}-$ Uropol S ${ }^{\circledR}$ ) } & \multirow{2}{*}{$\begin{array}{l}\text { i-PPS } 300 \mathrm{mg} \\
\left(\text { Elmiron }^{\mathbb{R}}\right)\end{array}$} & \multirow{2}{*}{$\begin{array}{l}\text { i-PPS } 200 \mathrm{mg}+\mathrm{o}-\mathrm{PPS} \\
400 \mathrm{mg}\left(\text { Elmiron }^{\mathbb{R}}\right) \\
\text { Davis et al. [38] }\end{array}$} \\
\hline & & Nickel et al. [35] & Nickel et al. [36] & & \\
\hline Cost per instillation & 1 & 1 & 1 & 0.4 & 0.6 \\
\hline Number of instillations & 6 & 6 & 8 & 24 & 36 \\
\hline Cost of treatment $(\mathrm{CT})$ & 6 & 6 & 8 & 9.6 & 21.6 \\
\hline \%Responders placebo/control & 0.182 & 0.233 & 0.313 & 0.200 & 0.90 \\
\hline$\%$ Responders active treatment & 0.933 & 0.4145 & 0.38 & 0.40 & 0.857 \\
\hline Odds ratio $(95 \% \mathrm{IC})$ & $76.5(6.08 ; 963.06)$ & $2.33(0.76 ; 7.17)$ & $1.35(0.58 ; 3.11)$ & $3.19(0.42 ; 24.38)$ & $0.67(0.10 ; 4.48)$ \\
\hline Absolute risk reduction $(95 \% \mathrm{CI})$ & $-0.75(-1-0 ;-0.50)$ & $-0.18(-2.88 ; 0.18)$ & $-0.07(-0.26 ; 0.12)$ & $-0.20(-0.59 ; 0.19)$ & $0.04(-0.16 ; 0.24)$ \\
\hline NNT $(95 \% \mathrm{CI})$ & $1.33(1.0 ; 2.0)$ & $5.51(2.4 ; 18.84)$ & $14.81(3.92 ; 8.31)$ & $2.67(0.36 ; 19.71)$ & $-23.33(-4.13 ; 6.40)$ \\
\hline Cost-effectiveness (CT/\%responders) & 6.43 & 14.49 & 21.05 & 21.62 & 25.20 \\
\hline Cost efficacy (CT $\left.{ }^{\mathrm{a} N N T s}\right)$ & 7.98 & 33.06 & 118.48 & 25.63 & 503.93 \\
\hline
\end{tabular}

$H M W-H A$ high molecular weight hyaluronic acid, $C S$ chondroitin sulphate, $i-P P S$ intravesical pentosan polysulphate, $o-P P S$ oral pentosan polysulphate, $N N T$ number needed to treat to obtain a response

${ }^{a}$ Response rates correspond to those presented in the articles [29, 30, 31, 33] and/or calculated by total of responders/total patients with per protocol results [32]

The present meta-analytical analysis adds important information to the body of published evidence and is partly contradictory to systematic reviews that have been published in the past. In particular, ES assessment of outcome parameters facilitates the comparison of results with different GAG products for BPS/IC.

Madersbacher et al. [7] searched the literature for all forms of chronic cystitis, including radiation cystitis and also OAB (which is not considered a form of chronic cystitis) and excluded all but 27 publications for further analysis. They concluded that $\mathrm{ChS}$ is superior to other intravesical GAG substitutes. However, in their review, 368 patients who were treated with $\mathrm{ChS}$ had a diagnosis of OAB, 20 patients a diagnosis of radiation cystitis [27], and only 118 patients were "exclusively" diagnosed with BPS/IC. The authors also state that no significant superiority versus controls was observed in the single controlled study on ChS $2 \%$ that was reviewed [35].

Giannantoni et al. [49] evaluated CTs and UCTs on a multitude of therapies for BPS/IC, including behavioural, dietary, interventional, pharmacological and surgical therapies. In their systematic review not a single study on HA therapy was included. Given the high number of publications on HA in BPS/IC reporting superiority to other intravesical agents, this review is presumably incomplete. The authors conclude that evidence of BPS/IC therapy is limited, and that only the oral drugs cyclosporine A and amitriptyline showed significant ES on the classical BPS/IC symptoms of pain and frequency/urgency.

Fall et al. [13] reviewed the literature to find an evidence base for treatment decisions in BPS/IC. Their conclusions were: level of evidence (LE) 1b/grade of recommendation
(GR) A for intravesical PPS, LE 2b/GR B for HA and for $\mathrm{ChS}$, and LE 3/GR C for intravesical heparin.

The review performed by Matsuoka et al. [50] included four treatment modalities for BPS/IC: resiniferatoxin, Bacillus Calmette-Guerin (BCG), oxybutynin and alkalinised lidocaine; as no GAG substitutes were evaluated, their results are not comparable with our analysis.

In conclusion, this meta-analytical review provides evidence of the positive effects of intravesical GAG therapy for BPS/IC and that this treatment may significantly improve patients' symptoms. Single reports even suggest that complete and permanent remission is possible in a subgroup of patients that has not yet been well defined [40, 42].

If medical and pharmacoeconomic aspects are combined, HMW-HA seems to have some advantage over other instillation agents. Despite these findings, direct comparisons between the different products have not been performed to date in properly designed controlled studies.

The present meta-analysis suffers from the limited number of controlled accessible studies on intravesical therapies for BPS/IC and non-standardised response criteria. Many studies had to be excluded because of noncomparable inclusion criteria, treatment combinations and evaluation instruments. However, it gives a complete summary of all the data currently available and, by assessing the effect size, makes it possible to compare the relevance of the individual studies.

Acknowledgements Dr Agustí Martí Gil and Dr Cindy L. Larios from the Medical Department of Clever Instruments S.L. (Barcelona, Spain) collaborated as independent reviewers. 


\section{Compliance with ethical standards}

Conflicts of interest J.M. Barua: consultancy and speaker's honoraria for/from Mylan; I. Arance: none; J.C. Angulo: none; C.R. Riedl: consultancy and speaker's honoraria for/from Mylan.

Funding Data and statistical analysis were funded by an unrestricted grant by Mylan.

Open Access This article is distributed under the terms of the Creative Commons Attribution 4.0 International License (http:// creativecommons.org/licenses/by/4.0/), which permits unrestricted use, distribution, and reproduction in any medium, provided you give appropriate credit to the original author(s) and the source, provide a link to the Creative Commons license, and indicate if changes were made.

\section{References}

1. Hanno P, Dmochowski R (2009) Status of international consensus on interstitial cystitis/bladder pain syndrome: 2008 snapshot. Neurourol Urodyn 28:274-286

2. Hurst RE, Roy JB, Min KW, Veltri RW, Marley G, Patton K, Shackelford DL, Stein P, Parsons CL (1996) A deficit of chondroitin sulfate proteoglycans on the bladder uroepithelium in interstitial cystitis. Urology 48:817-821

3. Parsons CL, Lilly JD, Stein P (1991) Epithelial dysfunction in nonbacterial cystitis (interstitial cystitis). J Urol 145:732-735

4. Parsons CL (1996) Potassium sensitivity test. Tech Urol 2:171-173

5. Daha LK, Riedl CR, Hohlbrugger G, Knoll M, Engelhardt PF, Pflüger H (2003) Comparative assessment of maximal bladder capacity, $0.9 \% \mathrm{NaCl}$ vs. $0.2 \mathrm{M} \mathrm{KCl}$, for the diagnosis of interstitial cystitis: a prospective controlled study. J Urol 170:807-809

6. Daha KL, Riedl CR, Lazar D, Simak R, Pflüger H (2008) Effect of intravesical glycosaminoglycan substitution therapy on bladder pain syndrome/interstitial cystitis, bladder capacity and potassium sensitivity. Scand J Urol 8:1-4

7. Madersbacher H, van Ophoven A, van Kerrebroeck PEVA (2013) GAG layer replenishment therapy for chronic forms of cystitis with intravesical glycosaminoglycans - a review. Neurourol Urodyn 32: 9-18

8. Von Heyden B, Schmid HP (2000) Intravesical therapy of interstitial cystitis. Urologe A 39:542-544

9. Rovner E, Propert KJ, Bresinger C, Wein AJ, Foy M, Kirkemo A et al (2000) Treatment used in women with interstitial cystitis: the interstitial cystitis data base (ICDB) study experience. The Interstitial Cystitis Data Base Study Group. Urology 26:940-945

10. Burkman RT (2004) Chronic pelvic pain of bladder origin: epidemiology, pathogenesis and quality of life. J Reprod Med 49:225-229

11. Nickel JC, Moldwin R, Lee S, Davis EL, Henry RA, Wyllie MG (2009) Intravesical alkalinized lidocaine (PSD597) offers sustained relief from symptoms of interstitial cystitis and painful bladder syndrome. BJU Int 103:910-918

12. Parkin J, Shea C, Sant GR (1997) Intravesical dimethyl sulfoxide (DMSO) for interstitial cystitis - a practical approach. Urology 49: 105-107

13. Fall M, Oberpenning F, Peeker R (2008) Treatment of bladder pain syndrome/interstitial cystitis 2008: can we make evidence-based decisions? Eur Urol 54:65-75

14. Moher D, Liberati A, Tetzlaff J, Altman DG, The PRISMA Group (2009) Preferred reporting items for systematic reviews and metaanalyses: the PRISMA statement. PLoS Med 6(7):e1000097
15. Morales A, Emerson L, Nickel J, Lundie M (1996) Intravesical hyaluronic acid in the treatment of refractory interstitial cystitis. J Urol 156:445-448

16. Riedl C, Engelhardt P, Daha K, Moraskis N, Pfluger H (2008) Hyaluronan treatment of interstitial cystitis/painful bladder syndrome. Int Urogynecol J 19:717-721

17. Daha LK, Lazar D, Simak R, Pfluger H (2008) The effects of intravesical pentosanpolysulfate treatment on the symptoms of patients with BPS/IC: preliminary results. Int Urogynecol J 19: 987-990

18. Cohen J (1988) Statistical power analysis for the behavioural sciences, 2nd edn. Erlbaum, Hillsdale

19. Lv YS, Zhou HL, Mao HP, Gao R, Wang YD, Xue XY (2012) Intravesical hyaluronic acid and alkalinized lidocaine for the treatment of severe painful bladder syndrome/interstitial cystitis. Int Urogynecol J 23:1715-1720

20. Daha LK, Riedl CR, Lazar D, Hohlbrugger G, Pfluger H (2005) Do cystometric findings predict the results of Intravesical hyaluronic acid in women with interstitial cystitis? Eur Urol 47:393-397

21. Hung MJ, Chen YT, Shen PS, Hsu ST, Chen GD, Ho ESC (2012) Risk factors that affect the treatment of interstitial cystitis using intravesical therapy with a dimethyl sulfoxide cocktail. Int Urogynecol J 23:1533-1539

22. Gafni-Kane A, Botros SM, Du H (2013) Measuring the success of combined intravesical dimethylsulfoxide and triamcinolone for treatment of bladder pain syndrome/interstitial cystitis. Int Urogynecol J 24:303-311

23. Cervigni M, Natale F, Nasta L, Padoa A, Lo Voi R, Porru D (2008) A combined intravesical therapy with hyaluronic acid and chondroitin for refractory painful bladder syndrome/interstitial cystitis. Int Urogynecol J 19:943-947

24. Porru D, Cervigni M, Nasta L, Natale F, Lo Voi R, Tinelli C et al (2008) Results of endovesical hyaluronic acid/chondroitin sulfate in the treatment of interstitial cystitis/painful bladder syndrome. Rev Recent Clin Trials 3:126-129

25. Gauruder-Burmester A, Wildt B, Tunn R (2006) Treatment of overactive bladder with sodium chondroitin sulphate. Zentralbl Gynakol 128:336-340

26. Gauruder-Burmester A, Popken G (2009) Follow-up at 24 months after treatment of overactive bladder with $0.2 \%$ sodium chondroitin sulfate. Aktuelle Urol 40:355-359

27. Hazewinkel MH, Stalpers LJA, Dijkgraaf MG, Roovers JWR (2011) Prophylactic vesical instillations with $0.2 \%$ chondroitin sulfate may reduce symptoms of acute radiation cystitis in patients undergoing radiotherapy for gynecological malignancies. Int Urogynecol J 22:725-730

28. Parsons CL (2005) Successful downregulation of bladder sensory nerves with combination of heparin and alkalinized lidocaine in patients with interstitial cystitis. Urology 65:45-48

29. Parsons CL, Zupkas P, Proctor J, Koziol J, Franklin A, Giesing D et al (2012) Alkalinized lidocaine and heparin provide immediate relief of pain and urgency in patients with interstitial cystitis. J Sex Med 9:207-212

30. Porru D, Campus G, Tudino D, Valdes E, Vespa A, Scarpa R, Usai E (1997) Results of treatment of refractory interstitial cystitis with intravesical hyaluronic acid. Urol Int 59:26-29

31. Figuereido AB, Palma P, Riccetto C, Hermann V, Dambros M, Capmartin R (2011) Clinical and urodynamic experience with intravesical hyaluronic acid in painful bladder syndrome associated with interstitial cystitis. Actas Urol Esp 35:184-187

32. Cervigni M, Natale F, Nasta L, Mako A (2012) Intravesical hyaluronic acid and chondroitin sulphate for bladder pain syndrome/interstitial cystitis: long-term treatment results. Int Urogynecol J 23:1187-1192 
33. Sorensen RB (1996) Chondroitin sulphate in the treatment of interstitial cystitis and chronic inflammatory disease of the urinary bladder. Eur Urol 2:16-18

34. Shao Y, Shen ZJ, Rui WB, Zhou WL (2010) Intravesical instillation of hyaluronic acid prolonged the effect of bladder hydrodistention in patients with severe interstitial cystitis. Urology 75:547-550

35. Nickel JC, Egerdie B, Steinhoff G, Palmer B, Hanno P (2010) A multicenter, randomized, double-blind, and parallel groups: pilot evaluation of the efficacy and safety of intravesical sodium chondroitin sulfate versus vehicle control in patients with IC/PBS. Urology 76:804-809

36. Nickel JC, Hanno P, Kumar K, Thomas H (2012) Effectiveness and safety of intravesical sodium chondroitin sulfate compared with inactive vehicle control in subjects with interstitial cystitis/bladder pain syndrome. Urology 79:1220-1224

37. Bade JJ, Laseur M, Nieuwenburg A, van der Weele LT, Mensink HJA (1997) A placebo-controlled study of intravesical pentosan polysulphate for the treatment of interstitial cystitis. Br J Urol 79: 168-171

38. Davis EL, El Khoudary SR, Talbott EO, Davis J, Regan LJ (2008) Safety and efficacy of the use of intravesical and oral pentosan polysulfate sodium for interstitial cystitis: a randomized doubleblind clinical trial. J Urol 179:177-185

39. Sairanen J, Leppilahti M, Tammela TLJ, Paananen I, Aaltomaa S, Taari K, Ruutu M (2009) Evaluation of health-related quality of life in patients with painful bladder syndrome/interstitial cystitis and the impact of four treatments on interstitial cystitis? Scand J Urol Nephrol 43:212-219

40. Engelhardt PF, Morakis N, Daha LK, Esterbauer B, Riedl CR (2011) Long-term results of intravesical hyaluronan therapy in bladder pain syndrome/interstitial cystitis. Int Urogynecol J 22: $401-405$
41. Lai MC, Kuo YC, Kuo HC (2013) Intravesical hyaluronic acid for interstitial cystitis/painful bladder syndrome. A comparative randomized assessment of different regimens. Int J Urol 20:203-207

42. Kallestrup E, Jorgensen S, Nordling J, Hald H (2005) Treatment of interstitial cystitis with Cystistat ${ }^{\mathbb{R}}$ : a hyaluronic acid product. Scand J Urol Nephrol 39:143-147

43. Gupta SK, Pidcock L, Parr NJ (2005) The potassium sensitivity test: a predictor of treatment response in interstitial cystitis. BJU Int 96:1063-1066

44. Steinhoff G (2003) The efficacy of chondroitin sulphate in treating interstitial cystitis. Eur Urol Suppl 2:14-16

45. Nordling J, van Ophoven A (2008) Intravesical glycosaminoglycan replenishment with chondroitin sulphate in chronic forms of cystitis. A multi-national, multi-centre, prospective observational clinical trial. Arzneitmittelforschung 58:328-335

46. Nickel J, Egerdie B, Downey J, Singh R, Skehan A, Carr L, IrvineBird K (2008) A real-life multicenter clinical practice study to evaluate the efficacy and safety of intravesical chondroitin sulphate for the treatment of interstitial cystitis. BJU Int 103:56-60

47. Porru D, Leva F, Parmigiani A, Barletta D, Choussos D, Gardella B et al (2011) Impact of intravesical hyaluronic acid and chondroitin sulfate on bladder pain syndrome/interstitial cystitis. Int Urogynecol J 23:1193-1199

48. Bade JJ, Mensink HJ, Laseur M (1995) Intravesical treatment of interstitial cystitis with a heparin analogue. Br J Urol 75:260

49. Giannantoni A, Bini V, Dmochowski R, Hanno P, Nickel JC, Proietti S, Wyndaele JJ (2012) Contemporary management of the painful bladder: a systematic review. Eur Urol 61:29-53

50. Matsuoka PK, Hadda JM, Pacetta AM, Baracat EC (2012) Intravesical treatment of painful bladder syndrome: a systematic review and meta-analysis. Int Urogynecol J 23:1147-1153 